\title{
Study of Normal Egyptian cervical Spinal Canal Using Different Radiological Modalities By
}

Mohammed A. Desouky,(1), Salwa M. Ouies (2), Mohamed M. Fadel(3), Mena N. Zakher,(4)

1. Prof. of Anatomy \& Embryology, Faculty of Medicine, El-Minia University.

2. Lecturer of Human anatomy \& Embryology, Faculty of Medicine, Sohag University.

3. Lecturer of Human anatomy \& Embryology, Faculty of Medicine, Ain Shams University.

4. Assistant Lecturer of Human anatomy \& Embryology, Faculty of Medicine,Sohag University.

\section{ABSTRACT}

Introduction: Decline in the size of Spinal canal would increase chance of compression of important structures and might lead to many symptoms including neck pain, and radiculopathy. Diagnosis of Spinal stenosis based on clinical findings along with the radiological assessing of the canal size measuring antero-posterior diameter and crosssectional area which are different for each population.

Many factors suggested affecting the spinal canal diameters such as race, sex, height and age which is still a controversial factor.

Aim of the work: The present study carried out to provide normal values of the cervical spinal canal dimensions in male Egyptian population and to evaluate the effect of aging.

Subjects and methods: MRI of 24 and CT of 32 male Egyptian subjects in different ages from 20 to 70 years. The population divided into three age groups (20-39 years, 40-59 years and 60 years and older). For each age group; Mid-sagittal antro-posterior diameter and Cross sectional area was measured from C2-C7.

Results: Mean values of the cervical canal diameters found to be widely variable fromC 2 to $\mathrm{C} 7$, and normal diameters defined as antero-posterior (APD) ranged (from 9.60to20 $\mathrm{mm}$ ), and (from 11.2to19.5mm) in CT and MRI respectively. Mid-sagittal antero-posterior canal diameter and Cross sectional area, decreased steadily with age at all levels.

Conclusion: Mean values for the cervical canal diameters decreased steadily at all levels with increase in age.

Keywords: cervical spinal canal, age, Egyptian males

\section{INTRODUCTION}

The Spinal canal has a complex anatomy and contains highly important structures such as spinal canal, and spinal nerves. Decline in the size of this canal which called spinal canal stenosis would increase chance of compression of these important structures and might lead to many symptoms including neck pain, and radiculopathy which represent a major health care problem with high prevalence $\left.^{(5,19}\right)$.

Due to their relative high mobility; Spinal stenosis is most common in the cervical and lumbar areas ${ }^{(\mathbf{1 4})}$.

Diagnosis of Spinal stenosis based on clinical findings along with the radiological assessing of the canal size (17).

Although there are many diameters to be measured for diagnosis of canal stenosis; the most accurate diameters for the central canal are anteroposterior diameter and cross-sectional area ${ }^{(20,23)}$.

Due to importance of the canal size for diagnosis of many pathological conditions, many studies done to evaluate normal spinal canal diameters in different populations using different radiological modalities $(\mathbf{2 1 , 6 , 1 2 )}$.

Studies which compared between different populations as regarding the spinal canal reported that minimum 
SOHAG MEDICAL JOURNAL Study of Normal Egyptian cervical Spinal Canal Using

and maximum ranges of spinal canal diameters are different for each population $^{(\mathbf{1}, \mathbf{4})}$.

Many factors suggested affecting the spinal canal diameters such as race, sex, height and age. Age is a controversial factor; many authors reported that spinal canal diameters decrease significantly with ageing. However other studies reported that age is not associated with significant spinal canal variations in normal people $^{(3,11,1)}$.

AIM OF THE WORK: The present study designed to provide normal values of the cervical spinal canal dimensions in male Egyptian population and to evaluate effect of aging Using Different Radiological Modalities.

\section{SUBJECTS AND METHODS}

The population studied: MRI of 24 and CT of 32 Egyptian males in different ages from 20 to 70 years meet inclusion criteria ; images which obtained for various reason rather than complaints related to the spine such as; those done for abdomino-pelvic problems, metastatic tumors, muscle pain, and soft tissue injuries. Images were examined by radiologist to exclude any radiological evidences of fracture, congenital anomalies, degenerative changes, endplate sclerosis, spinal metastasis, previous spinal surgery or any other pathology. The study was done during 2017. MRI and CT images collected from Sohag University; The CT machine was TOSHIBA, Japanese (multislice 16)\& The MRI machine used was HITACHI, Japanese (0.3 tsla).
Images divided into three groups according to age;

V Group1; Age at 20-39 years (CT of 12 subjects\& MRI of 8 subjects).

V Group2; Age at 40-59 years (CT of 12 subjects\& MRI of 8 subjects).

v Group3; Age at 60 years and older

(CT of 8 subjects\& MRI of 8 subjects).

\section{Methods for measurements:}

The obtained images were stored in a computerized system that allowed enhancement, magnification, and rotation and had a measuring tool.

For MRI or CT of each subject; Measurements were obtained on the axial cuts at the mid-vertebral level (C2, C3, C4, C5, C6, and C7).

1. Mid-sagittal antro-posterior diameter: line was drawn in the midline from the posterior aspect of the spinal canal (the anterior aspect of the base of the spine) to the anterior aspect of the canal (the posterior border of the vertebral body). (Fig.1)

2. Cross sectional area: A circle was drawn whereas its border was the vertebral canal (vertebral body, pedicles, laminae and base of the spine). (Fig.1)

Data was analyzed using STATA intercooled version 12.1. Quantitative data was represented as mean, standard deviation, median and range. Data was analyzed using ANOVA with post hoc Bonferroni test for comparison of the means of three groups. Graphs were produced by using Excel or STATA program. $\mathrm{P}$ value was considered significant if it was less than 0.05 


\section{RESULTS:}

A. The antero-posterior diameter:

1. Computerized tomography (CT):

Mean values of the antero-posterior diameter for all ages were $15.96( \pm 1.82) \mathrm{mm}$, $12.48( \pm 1.33) \mathrm{mm}, 11.92( \pm 1.40) \mathrm{mm}, 12.54( \pm 1.64), 12.38 \mathrm{~mm},( \pm 1.73) \mathrm{mm}$ and $12.58( \pm 1.45) \mathrm{mm}$ respectively at $2 \mathrm{nd}, 3 \mathrm{rd}, 4 \mathrm{th}, 5 \mathrm{th}, 6 \mathrm{th}$, and 7 th cervical vertebral

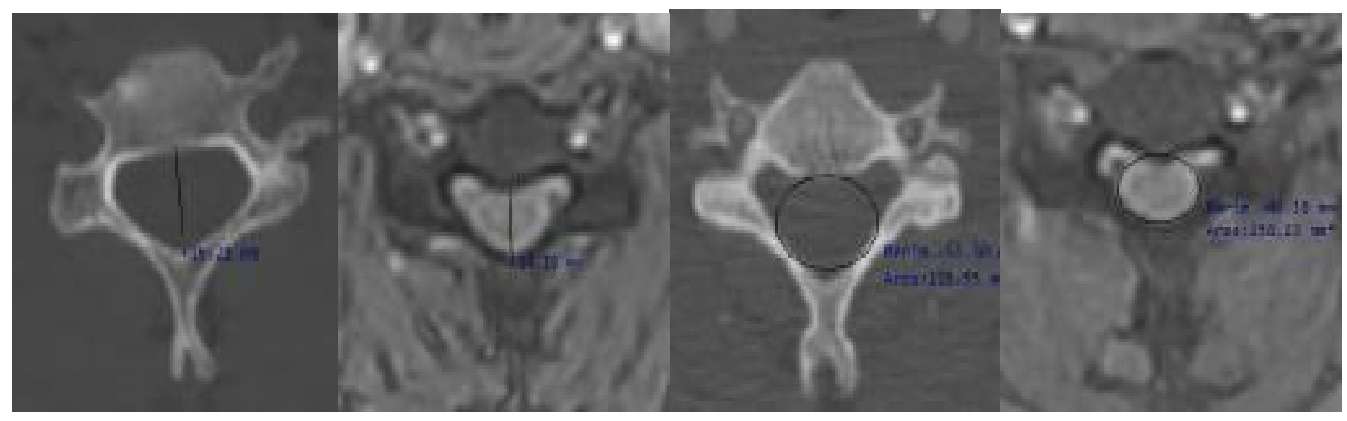

(Figure 1): The Images showing;

(A) And (B) measuring the antero-posterior (APD) diameter of the cervical bony spinal canal; using (A) A CT scan (B) A T2-Weighted MR

(C)And (D) measuring the cross sectional area (CSA)of the cervical bony spinal canal; using (C) A CT scan(D) A T2-Weighted MR

levels.

The mean values of the antero-posterior diameter for each age group presented in Table (1) and (Fig.2).

\section{Magnetic resonance imaging (MRI):}

Mean values of the antero-posterior diameter(APD) for all ages were $15.13( \pm 1.59)$ $\mathrm{mm}, 13.31( \pm 1.18) \mathrm{mm}, 12.63( \pm 1.05) \mathrm{mm}, 12.90( \pm 1.04), 13.24 \mathrm{~mm},( \pm 1.25) \mathrm{mm}$ and $13.90( \pm 1.25) \mathrm{mm}$ respectively at $2 \mathrm{nd}, 3 \mathrm{rd}, 4 \mathrm{th}, 5 \mathrm{th}, 6 \mathrm{th}$, and 7 th cervical vertebral levels.

The mean values of the antero-posterior diameter for each age group presented in Table (2) and (Fig.3).

\section{B.the cross sectional area(CSA):}

1. Computerized tomography (CT):

Mean values of the cross sectional area(CSA)for all ages were $223.17( \pm 33.02) \mathrm{mm} 2$, $146.65( \pm 24.21) \mathrm{mm} 2,136.24( \pm 23.94) \mathrm{mm} 2,150.38( \pm 36.98) \mathrm{mm} 2,145.11( \pm 33.69)$ $\mathrm{mm} 2$ and $144.24( \pm 46.81) \mathrm{mm} 2$ respectively at 2nd, 3rd, 4th, 5th, 6th, and 7th cervical vertebral levels.

The mean values of the cross sectional area (CSA) for each age group presented in Table (3) and (Fig.4)

\section{Magnetic resonance imaging (MRI):}

Mean values of the cross sectional area(CSA)for all ages were $225.49( \pm 38.71) \mathrm{mm} 2$, $180( \pm 32.33) \mathrm{mm} 2,159.29( \pm 22.29) \mathrm{mm} 2,164.66( \pm 29.35) \mathrm{mm} 2,168.29( \pm 28.29) \mathrm{mm} 2$ and $184.36( \pm 33.19) \mathrm{mm} 2$ respectively at $2 \mathrm{nd}$, 3rd, 4th, 5th, 6th, and 7 th cervical vertebral levels

The mean values of the cross sectional area (CSA) for each age group presented in Table (4) and (Fig.5).

(Table 1): A Table showing Antero-posterior (APD) diameters of cervical spinal canal as measured by $\mathrm{CT}$ with Comparison among the three-age groups 
SOHAG MEDICAL JOURNAL Study of Normal Egyptian cervical Spinal Canal Using Vol. 22 No.3 October 2018 Mena N. Zakher

(Table 2): A Table showing Antero-posterior (APD) diameters of cervical spinal canal as measured by MRI, with Comparison among the three-age groups

\begin{tabular}{|c|c|c|c|c|c|c|c|}
\hline $\begin{array}{c}\text { Cervical } \\
\text { vertebra }\end{array}$ & Group (1) & Group (2) & Group (3) & P & P1 & P2 & P3 \\
\hline C2 Mean \pm SD & $16.89 \pm 1.05$ & $16.56 \pm 1.33$ & $13.66 \pm 1.45$ & 0.000 & 1.000 & 0.000 & 0.000 \\
\hline C3 Mean \pm SD & $13.08 \pm 1.41$ & $12.73 \pm 0.96$ & $11.20 \pm 0.89$ & 0.03 & 1.000 & 0.003 & 0.019 \\
\hline C4 Mean \pm SD & $12.71 \pm 1.61$ & $11.74 \pm 0.89$ & $10.99 \pm 1.06$ & 0.019 & 0.212 & 0.018 & 0.623 \\
\hline C5 Mean \pm SD & $12.80 \pm 1.77$ & $12.77 \pm 1.31$ & $11.80 \pm 1.85$ & 0.354 & 1.000 & 0.585 & 0.614 \\
\hline C6 Mean \pm SD & $12.64 \pm 1.84$ & $12.39 \pm 1.70$ & $11.98 \pm 1.75$ & 0.718 & 1.000 & 1.000 & 1.000 \\
\hline C7 Mean \pm SD & $12.97 \pm 1.29$ & $12.59 \pm 1.39$ & $12.00 \pm 1.72$ & 0.354 & 1.000 & 0.460 & 1.000 \\
\hline
\end{tabular}

\begin{tabular}{|c|c|c|c|c|c|c|c|}
\hline $\begin{array}{c}\text { Cervical } \\
\text { vertebra }\end{array}$ & Group (1) & Group (2) & Group (3) & P & P1 & P2 & P3 \\
\hline C2 Mean \pm SD & $16.08 \pm 0.44$ & $15.37 \pm 1.34$ & $13.75 \pm 1.23$ & 0.000 & 0.128 & 0.000 & 0.010 \\
\hline C3 Mean \pm SD & $14.32 \pm 0.45$ & $13.37 \pm 1.17$ & $12.31 \pm 0.94$ & 0.002 & 0.242 & 0.001 & 0.080 \\
\hline C4 Mean \pm SD & $13.20 \pm 0.78$ & $12.67 \pm 0.95$ & $11.96 \pm 0.93$ & 0.029 & 0.663 & 0.026 & 0.357 \\
\hline C5 Mean \pm SD & $13.61 \pm 0.65$ & $13.10 \pm 0.88$ & $12.01 \pm 0.91$ & 0.003 & 0.685 & 0.003 & 0.047 \\
\hline C6 Mean \pm SD & $13.68 \pm 0.54$ & $13.14 \pm 1.18$ & $12.31 \pm 1.41$ & 0.030 & 1.00 & 0.050 & 0.058 \\
\hline C7 Mean \pm SD & $14.52 \pm 0.61$ & $14.11 \pm 1.05$ & $13.02 \pm 1.45$ & 0.027 & 1.00 & 0.041 & 0.082 \\
\hline
\end{tabular}

$\mathrm{P}$ compared the 3 groups, $\mathrm{p} 1$ compared group (1) \& (2),P2 compared group (1) \& (3), p3 compared group (2) \& (3); Significant at $\mathrm{p}<0.05$

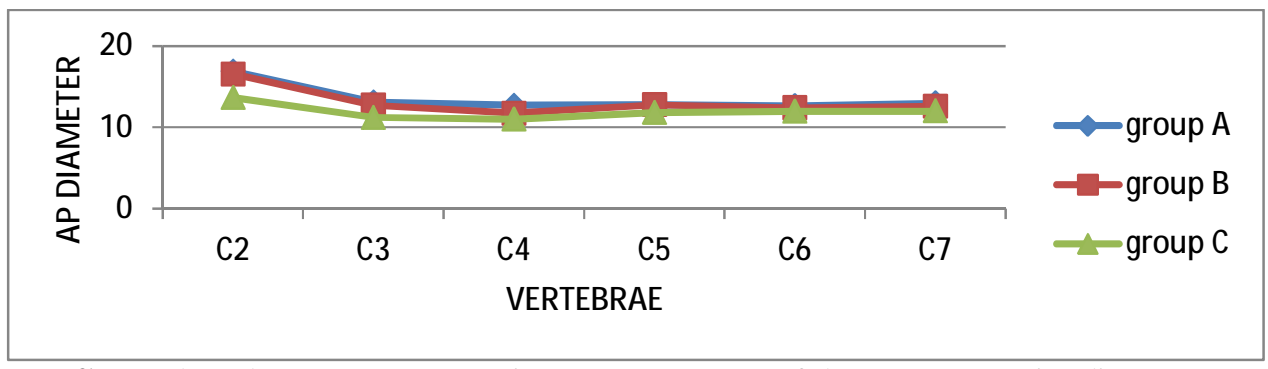

(Figure 2): A Chart demonstrate Comparison among means of the antero-posterior diameter (A-P) of cervical vertebrae as measured by CT; the three-age groups; group (1)(20-39), group (2)(40-59), group $(3)(\geq 60)$

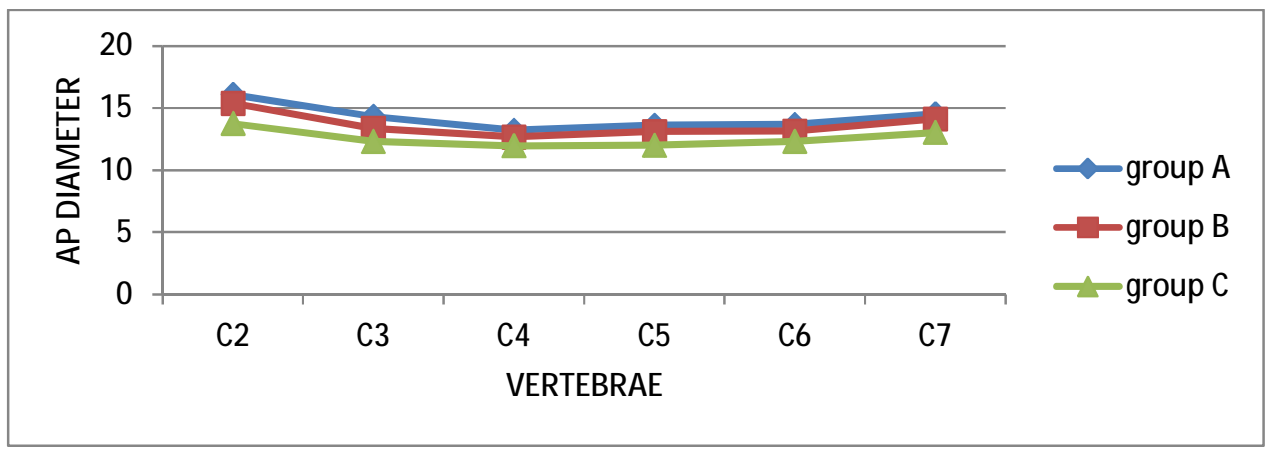

(Figure 3): A Chart demonstrate Comparison among means of the antero-posterior diameter (A-P) of cervical vertebrae as measured by MRI; the three-age groups; group (1)(20-39), group (2)(40-59), group $(3)(\geq 60)$ 
SOHAG MEDICAL JOURNAL Study of Normal Egyptian cervical Spinal Canal Using Vol. 22 No.3 October 2018 Mena N. Zakher

(Table 3): A Table showing Cross sectional (CS) Area of cervical spinal canal as measured by $\mathrm{CT}$ with Comparison among the three-age groups as regard CS

\begin{tabular}{|l|c|c|c|c|c|c|c|}
\hline Cervical vertebra & Group (1) & Group (2) & Group (3) & P & P1 & P2 & P3 \\
\hline $\begin{array}{l}\text { C2 } \\
\text { Mean } \pm \text { SD }\end{array}$ & $239.83 \pm 23.66$ & $235.66 \pm 26.91$ & $182.2 \pm 23.74$ & $<0.0001$ & 1.00 & $<0.0001$ & $<0.0001$ \\
\hline $\begin{array}{l}\text { C3 } \\
\text { Mean } \pm \text { SD }\end{array}$ & $157.2 \pm 29.59$ & $151.43 \pm 14.92$ & $124.48 \pm 9.04$ & 0.005 & 1.00 & 0.006 & 0.021 \\
\hline $\begin{array}{l}\text { C4 } \\
\text { Mean } \pm \text { SD }\end{array}$ & $151.22 \pm 33.24$ & $135.33 \pm 21.31$ & $113.4 \pm 7.38$ & 0.009 & 0.443 & 0.007 & 0.06 \\
\hline $\begin{array}{l}\text { C5 } \\
\text { Mean } \pm \text { SD }\end{array}$ & $161.22 \pm 34.46$ & $157.76 \pm 36.23$ & $123.03 \pm 28.512$ & 0.047 & 1.00 & 0.05 & 0.109 \\
\hline $\begin{array}{l}\text { C6 } \\
\text { Mean } \pm \text { SD }\end{array}$ & $156.20 \pm 33.69$ & $148.43 \pm 34.50$ & $125.26 \pm 22.1$ & 0.127 & 0.95 & 0.142 & 0.397 \\
\hline $\begin{array}{l}\text { C7 } \\
\text { Mean } \pm \text { SD }\end{array}$ & $162.74 \pm 29.79$ & $138.21 \pm 63.07$ & $125.64 \pm 30.8$ & 0.189 & 0.608 & 0.249 & 1.00 \\
\hline
\end{tabular}

(Table (4): A Table showing Cross sectional (CS) Area of cervical spinal canal as measured by MRI with Comparison among the three-age groups

\begin{tabular}{|l|c|c|c|c|c|c|c|}
\hline cal vertebra & Group (1) & Group (2) & Group (3) & P & P1 & P2 & P3 \\
\hline $\begin{array}{l}\text { C2 } \\
\text { Mean } \pm \text { SD }\end{array}$ & $240.5 \pm 14.22$ & $239.14 \pm 43.79$ & $195.25 \pm 35.49$ & 0.021 & 1.00 & .042 & 0.048 \\
\hline $\begin{array}{l}\text { C3 } \\
\text { Mean } \pm \text { SD }\end{array}$ & $193.64 \pm 23.19$ & $189.86 \pm 31.77$ & $159.25 \pm 34.74$ & 0.078 & 1.00 & 0.119 & 0.196 \\
\hline $\begin{array}{l}\text { C4 } \\
\text { Mean } \pm \text { SD }\end{array}$ & $173.86 \pm 23.51$ & $162.14 \pm 14.47$ & $142.75 \pm 18.93$ & 0.012 & 0.735 & 0.011 & 0.150 \\
\hline $\begin{array}{l}\text { C5 } \\
\text { Mean } \pm \text { SD }\end{array}$ & $180.21 \pm 22.14$ & $173.14 \pm 19.56$ & $138.25 \pm 28.54$ & 0.004 & 1.00 & 0.005 & 0.020 \\
\hline $\begin{array}{l}\text { C6 } \\
\text { Mean } \pm \text { SD }\end{array}$ & $185.21 \pm 6.35$ & $177.29 \pm 23.77$ & $142 \pm 30.25$ & 0.002 & 1.00 & 0.017 & 0.020 \\
\hline $\begin{array}{l}\text { C7 } \\
\text { Mean } \pm \text { SD }\end{array}$ & $201.5 \pm 12.16$ & $190.14 \pm 29.36$ & $157.25 \pm 38.81$ & 0.015 & 1.00 & 0.02 & 0.069 \\
\hline
\end{tabular}

P compared the 3 groups, p1 compared group (1) \& (2), P2 compared group (1) \& (3), p3 compared group (2) \& (3); Significant at $\mathrm{p}<0.05$

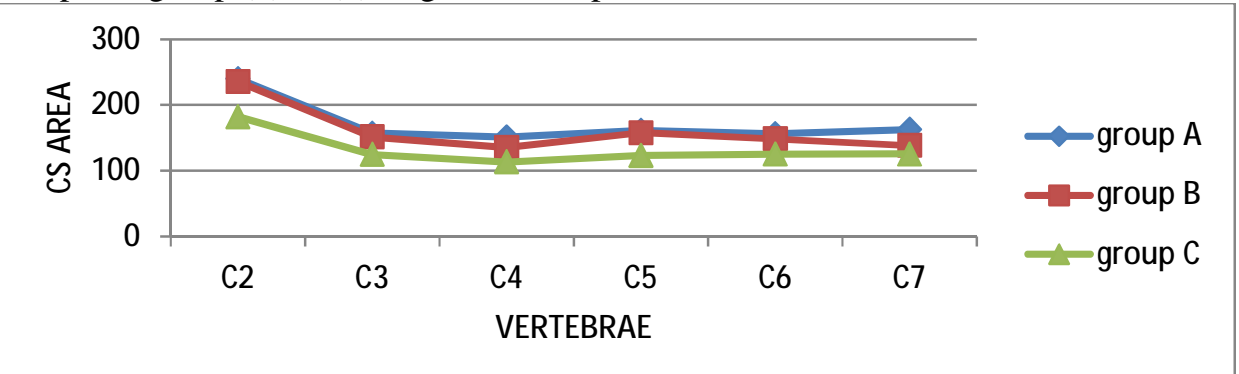

Figure (4): A Chart demonstrate Comparison among means of the Cross sectional (CS) Area of cervical vertebrae as measured by CT; the three-age groups; group (1)(20-39), group (2)(40-59), group $(3)(\geq 60)$

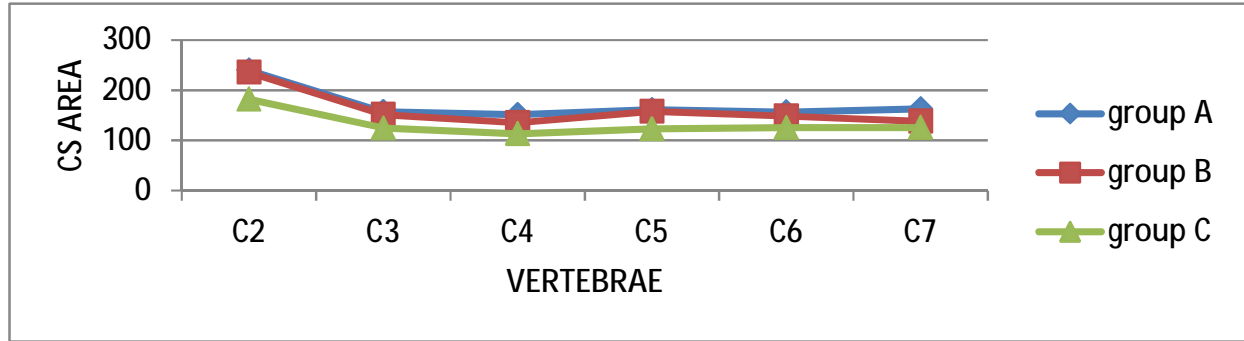

(Figure 5): A Chart demonstrate Comparison among means of the Cross sectional (CS) Area of cervical vertebrae as measured by CT; the three-age groups; group (1)(20-39), group (2)(40-59), group (3)( $\geq 60)$ 


\section{DISCUSSION}

This study tried to evaluate and define the normal dimensions of cervical spinal canal in male Egyptian population Measuring most frequently applied radiologic parameters include mid-sagittal diameter, and crosssectional area ${ }^{(15,18)}$. Also, the effect of age was studied.

All measures had taken at midvertebral levels to avoid introduction of further variables such as individually different degenerative changes,also male gender selected to avoid hormonal changes in females ${ }^{(23}$, 9).

The present study defined the normal range of male Egyptian cervical canal diameters; the antero-posterior (APD) from $\mathrm{C} 1$ to $\mathrm{C} 7$ ranged (from 9.60to20mm), and (from 11.2 to $19.5 \mathrm{~mm}$ ) in CT and MRI measurements respectively, which was in concordance with the study of Zhang et al., who stated that The mean sagittal diameter of cervical spinal canal at $\mathrm{C} 1$ to $\mathrm{C} 7$ ranges from 15.33 $\mathrm{mm}$ to $20.46 \mathrm{~mm}^{\text {(24) }}$.

Similarly Lee et al. found that anteriorposterior canal diameter in all specimens at all cervical levels was $14.1 \pm 1.6 \mathrm{~mm}$. The canal diameters ranged from 9.0 to $20.9 \mathrm{~mm}$, with a median diameter of $14.4 \mathrm{~mm}^{(17)}$.

Furtherly Gour et al., (2011) reported that mid sagittal diameter of Dry bone cervical vertebral canal - The mean values were $14.38( \pm 1.43) \mathrm{mm}, 14.40$ $( \pm 1.31) \mathrm{mm}, 14.36( \pm 1.32) \mathrm{mm}$ and $14.55( \pm 1.21) \mathrm{mm}$ respectively at $3 \mathrm{rd}$, 4th, 5th, and 6th cervical vertebral levels ${ }^{(13)}$

In the present study, both midsagittal antero-posterior canal diameter and Cross sectional area decreased steadily with age at all levels in both $\mathrm{CT}$ and MRI measurements. The values in group (1); (age 20-39) were significantly decreased when compared to both group (2); (age 40-59) and group (3); (age $\geq 60$ ) with no significance difference between Group (2) and Group (3). these came in agreement with the observations, Ulbrich et al. mentioned that all spinal levels effected by individual factors such as age, sex, and height which have statistically significant influence on the measurements ${ }^{(23)}$.

Recently in 2016 similar results were recorded by Abuelnor; who mentioned that there was a significant correlation between the age and spinal stenosis ${ }^{(2)}$. Furthermore Tacar et al. Saied that spinal stenosis syndrome affects mainly patients in their 5th- 6th decade of life ${ }^{(22)}$.

On the other hand, this disagrees with Kim et al. who reported that age is not associated with spinal canal width and length variations in thoracic and lumbar vertebrae in normal people ${ }^{(\mathbf{1 6})}$. Also Orha et al. found that age is an important factor for disc degeneration, vertebral height decreased with age, but spinal canal diameter did not change ${ }^{(\mathbf{2 0})}$.

According to Abd Alrahem and Hasan (2016) the relationship between the patient age and Anterio-posterior measurement in the axial cut was found to be a weak indirect relationship ${ }^{(\mathbf{1})}$.

Difference in the significance of aging effect between levels and methods could be attributed to presence of other factors which suggested having effect on spinal canal diameters, this explanation reported by many studies which found that There is an association between age, height and weight and the AP canal diameter ${ }^{(15}$, 11, 10).

\section{CONCLUSION}

For cervical canal (from $\mathrm{C} 2$ to $\mathrm{C} 7$ ), diameters found to be widely variable fromC2 to $\mathrm{C} 7$, and normal diameters defined as antero-posterior (APD) ranged (from 9.60to20mm), and (from 
SOHAG MEDICAL JOURNAL Study of Normal Egyptian cervical Spinal Canal Using

11.2to19.5mm) in CT and MRI respectively.

Cervical Spinal canal diameters, both midsagittal antero-posterior canal diameter and Cross sectional area, decreased steadily with age at all levels.

Difference in the significance of aging effect between levels and methods could be attributed to presence of other factors-which suggested having effect on spinal canal diameters-; such as height and weight.

\section{REFERENCES}

1- Abd-Alrahem, A. H., Hasan, H. A. (2016): Evaluation of Canal Diameter by MRI in Sudanese Population, American Scientific Research Journal for Engineering, Technology, and Sciences (ASRJETS), 22(1), 176-183.

2- Abuelnor, M. (2016): Morphometric study of the lumbar spinal canal and lumbar stenosis in Sudanese, Research gate; 4(12C):4372-4377.

3- AL-Anazi, A. R., Nasser, M., Moghazy, K., Hosam, A.-J., \& Osama, E.-H. (2007): Radiographic measurement of lumbar spinal canal size and canal/body ratio in normal adult Saudis. Neurosurgery Quarterly, 17(1), 19-22.

4- Alam, M. M., Waqas, M., Shallwani, H., \& Javed, G. (2014): Lumbar morphometry: a study of lumbar vertebrae from a Pakistani population using computed tomography scans,Asian spine journal; 8(4):421426.

5- Alvarez, J., \& Hardy, J. R. (1998): Lumbar spine stenosis: a common cause of back and leg pain, American family physician; 57(8): 1825-1834, 1839-1840.

6- Aly, T., \& Amin, O. (2013): Geometrical dimensions and morphological study of the lumbar spinal canal in the normal Egyptian population, Orthopedics; 36(2):e229e234.

7- Chatha, D. S., \& Schweitzer, M. E. (2011): MRI criteria of developmental lumbar spinal stenosis revisited,
Bulletin of the NYU hospital for joint diseases; 69(4): 303-307.

8- Chaudhary, S., Sarvesh, Pal Singh Batra, A., Gupta, R., \& Swami, S. (2015): A radiographic study of interpedicular distance of the lumbar vertebrae measured in plain anteroposterior radiographs, Int. J. of Adv. Res; 3 (8). 33-36

9- Elhassan, Y. A. M., Ali, Q. M., \& Ahmed, A. O. (2014): Sagittal diameter of the lumbosacral spinal canal in normal (asymptomatic) adult Sudanese population 2014. Sudan Medical Monitor, 9(4), 153-158.

10- Fetouh, F. A. (2015): age and gender related changes in midsagittal dimensions of the lumbar spine in normal egyptians: mri study. International journal of current research and review (ijcrr), 7(2), 21-40.

11- Gour, K., Shrivastava, S., \& Thakare, A. (2011): Size of cervical vertebral canal-measurements in lateral cervical radiographs and dried bones. Int J Biol Med Res, 2(3), 778-780.

12- John K Hsiang, (2016): Spinal stenosis, Medscape Website

13- Kathole, M., Joshi, R., Herekar, N., \& Jadhav, S. (2012): Dimensions of cervical spinal canal and vertebrae and their relevance in clinical practice. Int J Recent Trends Sci Tech, 3, 54-58.

14- Kim, K. H., Park, J. Y., Kuh, S. U., Chin, D. K., Kim, K. S., \& Cho, Y. E. (2013): Changes in spinal canal diameter and vertebral body height with age, Yonsei medical journal; 54(6): 1498-1504.

15- Lee, M. J., Cassinelli, E. H., \& Riew, K. D. (2007): Prevalence of cervical spine stenosis, Anatomic study in cadavers, J Bone Joint Surg Am; 89(2): 376-380.

16- Matveeva, N., Janevski, P., Nakeva, N., Zhivadinovik, J., \& Dodevski, A. (2013): Morphometric analysis of the cervical spinal canal on MRI, Prilozi; 34(2): 97-103.

17- Moore, K. L., Dalley, A. F., \& Agur, A. M. (2013): Clinically oriented anatomy, Third ED, Lippincott Williams \& Wilkins; 4:439-507.

18- Orha, A. T., Dalcik, C., \& Ilbay, K. (2016): Evaluation of Anthropometric 
SOHAG MEDICAL JOURNAL Study of Normal Egyptian cervical Spinal Canal Using

Characteristics Due to Sex and Age Variables of Lumbar Vertebra and Spinal Canal, The Anthropologist; 24(2): 617-622.

19- Santiago, F., Milena, G., Herrera, R., Romero, P., \& Plazas, P. (2001): Morphometry of the lower lumbar vertebrae in patients with and without low back pain, European Spine Journal; 10(3): 228-233.

20- Tacar, O., Dem $\ddot{A} \pm$ rant, A., Nas, K., \& Altinda $\ddot{A} \ddot{Y}$, O. (2003): Morphology of the lumbar spinal canal in normal adult Turks, Yonsei medical journal; 44(4): 679-685.

21- Ulbrich, E. J., Schraner, C., Boesch, C., Hodler, J., Busato, A., Anderson, S. E., Sturzenegger, M. (2014): Normative MR cervical spinal canal dimensions, Radiology; 271(1):172-182.

22- Zhang, L., Chen, H. B., Wang, Y., Zhang, L. Y., Liu, J. C., \& Wang, Z. G. (2012): Cervical spinal canal narrowing and cervical neurological injuries, Chin J Traumatol; 15(1): 3641. 